\title{
Immunological properties of recombinant classical swine fever virus NS3 protein in vitro and in vivo
}

\author{
Henriette RAU ${ }^{\mathrm{a}}$, Hilde REVETS ${ }^{\mathrm{b}}$, Carole BALMELLI ${ }^{\mathrm{a}}$, \\ Kenneth C. MCCULlOUGH ${ }^{\mathrm{a}}$, Artur SUMMERFIELD ${ }^{\mathrm{a} *}$ \\ a Institute of Virology and Immunoprophylaxis, 3147 Mittelhäusern, Switzerland \\ b Flanders Interuniversity, Institute for Biotechnology, Department of Molecular \\ and Cellular Interactions, Vrije Universiteit Brussel, Brussels, Belgium
}

(Received 7 July 2005; accepted 5 September 2005)

\begin{abstract}
Classical swine fever (CSF) is a highly contagious and often fatal disease of pigs characterised by fever, severe leukopenia and haemorrhages. With vaccines having an importance in disease control, studies are seeking improved protein-based subunit vaccine against the virus (CSFV). In this respect, recombinant viral NS3 protein was analysed for its immunopotentiating capacity, particularly in terms of cytotoxic immune responses. NS3 was effective at inducing in vitro responses, quantified by lymphoproliferation, IFN- $\gamma$ ELISPOT, flow cytometric detection of activated $\mathrm{T}$ cell subsets, and cytotoxic $\mathrm{T}$ cell assays. Peripheral blood mononuclear cells from CSFV-immune pigs could be stimulated, but not cells from naïve animals. In addition to the IFN- $\gamma$ responses, induction of both $\mathrm{CD} 4^{+} \mathrm{T}$ helper cell and $\mathrm{CD} 8^{+}$cytotoxic $\mathrm{T}$ cells (CTL) were discernible - activation of the latter was confirmed in a virus-specific cytolytic assay. Attempts were made to translate this to the in vivo situation, by vaccinating pigs with an E2/NS3-based vaccine compared with an E2 subunit vaccine. Both vaccines were similar in their abilities to stimulate specific immune responses and protect pigs against lethal CSFV infection. Although the E2/NS3 vaccine appeared to have an advantage in terms of antibody induction, this was not statistically significant when group studies were performed. It was also difficult to visualise the NS3 capacity to promote T-cell responses in vivo. These results show that NS3 has potential for promoting cytotoxic defences, but the formulation of the vaccine requires optimisation for ensuring that NS3 is correctly delivered to antigen presenting cells for efficient activation of CTL.
\end{abstract}

classical swine fever / subunit vaccine / E2 / NS3 / CTL

\section{INTRODUCTION}

Classical swine fever virus (CSFV), a member of the Pestivirus genus of the Flaviridae family, is an important worldwide cause of morbidity, mortality, and enormous economic losses in pig industries [12, 23]. While eradication programmes based on "stamping-out" have been followed to eliminate classical swine fever (CSF) in many countries, these pig populations remain under constant threat, particularly where CSFV is enzootic in wild boars. With such situations, an important control instrument is vaccination, alone or combined with stamping-out [28].

Traditional avirulent live vaccines such as the $\mathrm{C}$-strain exist and are efficient, but do

\footnotetext{
* Corresponding author: Artur.Summerfield@ivi.admin.ch
} 
not permit the distinction of pigs infected with field strains of CSFV from vaccinated animals. Accordingly, protein subunit vaccines based on the immunodominant viral glycoprotein E2 have been developed [15, $24,37]$. These "marker vaccines" enable the discrimination between infected and vaccinated animals (DIVA) [24], and allow vaccination during outbreaks as an anti-viral measure. Their disadvantage lies in the observation that efficient protection against infection is only ensured three weeks postvaccination. Early after vaccination, the E2 vaccine cannot prevent infection, which could lead to chronically or persistently infected piglets, particularly if pregnant sows are affected (reviewed by [36]). The potency of the E2 subunit vaccines is based mainly on induction of an effective humoral immune response, measurable as virus-neutralising antibodies [4, 5, 15, 37, 38]. Nevertheless, animals inoculated with an E2 subunit vaccine are unable to prevent horizontal and vertical spread of the virus [11].

Consequently, there is a need to improve the immunogenicity of subunit vaccines, which are of considerable value in the control of CSF due to their advantages of safety and established DIVA tests [10, 13, 24]. One area of importance in this respect is the induction of virus-specific cytotoxic T lymphocytes (CTL), an important defence mechanism against non-cytopathogenic virus infections such as CSF. This immunological effector mechanism plays a major role in the elimination of chronically/persistently infected cells [39]. Indeed, recent studies on CSF indicate an important role for cellmediated immune responses in protection against the virus [31]. Thus, the induction of potent $\mathrm{CD}^{+}$cytotoxic $\mathrm{T}$ cell responses has the potential to improve CSF vaccines. Consequently, the present study analysed the immunological properties of recombinant NS3, due to the observations that CSFV non-structural proteins carry $\mathrm{T}$ cell epitopes $[1,25]$. This was analysed in vitro and in vivo in terms of its contribution to protective immune responses induced in combination with an E2 subunit vaccine.

\section{MATERIALS AND METHODS}

\subsection{Virus}

The CSFV strains Eystrup [20] and Alfort [27] were propagated in swine kidney (SK)6 cells at a multiplicity of infection (MOI) of $0.01 \mathrm{TCID}_{50} /$ cell for $72 \mathrm{~h}$ at $39{ }^{\circ} \mathrm{C}$ and $6 \% \mathrm{CO}_{2}$. Cell associated virus was released by sonificating the cells and clarification of the cell lysates as described [17]. For mock controls, clarified lysates of uninfected cells were employed. Virus titres were determined by endpoint dilution titrations on SK-6 cells as described previously [17].

\subsection{CSFV-derived antigens}

\subsubsection{Expression and purification of $6 \times$ his-tagged NS3}

NS3 derived from the CSFV strain Alfort Tübingen was cloned in the prokaryotic expression vector pQE-82L (kindly donated by Dr D. Wienhold, FLI, Tübingen, Germany). After transformation of E. coli BL21 RIL competent cells, protein production in $E$. coli was induced following the manufacturer's instructions (Qiagen, The Netherlands). The recombinant protein expressed with a $6 \times$ his-tag was purified under denaturating conditions by immobilised metal affinity chromotography (IMAC) using Ni-NTA resin (Qiagen). The eluted protein was further purified from contaminating proteins by continuous elution SDSPAGE electrophoresis. The fractions were combined, concentrated and further purified by size exclusion chromatography via HPLC (AEKTA explorer, Amersham Pharmacia Biotech, The Netherlands) using Superdex-75 HR10/30 (Amersham Pharmacia Biotech) equilibrated with a buffer containing $20 \mathrm{mM}$ Tris- $\mathrm{HCl}, \mathrm{pH} 8.0,100 \mathrm{mM}$ $\mathrm{NaCl}$ and $0.01 \%$ SDS. Finally, the proteins were analysed for endotoxin contamination using the Limulus Amoebocyte Lysate Assay (Bio-Whittaker). 


\subsubsection{Expression and purification of baculovirus expressed E2}

The E2 glycoprotein gene of CSFV was obtained from plasmid pA187-1 [27] and subcloned into plasmid pFastBac1 (Invitrogen, Basel, Switzerland) using standard PCR-based techniques. Briefly, the E2 gene lacking the sequence coding for the C-terminal transmembrane region was inserted downstream of the $\mathrm{gX}$ signal sequence of pseudorabies virus [15] and upstream of a cassette encoding 6 histidine residues. Recombinant baculovirus was then generated with the Bac-To-Bac Baculovirus Expression System (Invitrogen) and used to infect High Five cells for the production of secreted glycosylated protein E2. The supernatant of infected cells was subjected to buffer exchange with loading buffer for Ni-NTA columns $(0.02 \mathrm{M}$ sodium phosphate and $0.5 \mathrm{M} \mathrm{NaCl}$, pH 8.2) using a Stirred Ultrafiltration Cell (Amicon, Millipore, Volketswil, Switzerland) and a YM-10 ultrafiltration membrane (Millipore). The E2 protein was purified by nickel chelate affinity chromatography using an AEKTA FPLC apparatus (Amersham Bioscience, Otelfingen, Switzerland) and prepacked HiTrap Chelating columns (Amersham Bioscience). Fractions containing the purified E2 protein were analysed by SDSPAGE and pooled prior to quantification using the BCA protein assay (Bio-Rad).

\subsection{Animals and animal experimentation}

Swiss White Landrace pigs were kept under specific pathogen free (SPF) conditions at the institute. For analysis of secondary in vitro immune responses, a total of four pigs were vaccinated by infection with $10^{3}$ tissue culture infectivity dose $50 \%$ (TCID $_{50}$ ) low virulent CSFV strain Alfort [27], and used as blood donors 1-8 months post vaccination (p.v.).

In order to test the vaccines, two groups of four SPF pigs were vaccinated once intramuscularly (i.m.) in the neck. One group was immunised with a vaccine formulation containing $32 \mu \mathrm{g}$ E2 antigen, a second group received a mixture of $32 \mu \mathrm{g}$ $\mathrm{E} 2$ and $50 \mu \mathrm{g}$ NS3 antigen per $1 \mathrm{~mL}$ immunisation dose. Both vaccines were formulated by emulsifying the CSFV-derived antigens in a double water-oil-water emulsion (Montanide ISA 206 (w/v)), kindly provided by Dr L. Dupuis (Seppic, France). One control group of two SPF pigs was not inoculated. After 14 days, all pigs were challenged intranasally with a lethal dose of virulent CSFV strain Eystrup ( $10^{5}$ TCID $_{50}$ /animal) [20]. The animals were examined daily for disease symptoms and fever and scored as described [22]. Fever was defined as a rectal temperature $>40^{\circ} \mathrm{C}$. At various time points before and after the challenge infection, blood and serum samples were collected.

\subsection{Virus titres and neutralising antibodies}

Virus titres of serum samples were determined by endpoint dilution titrations [17]. The detection limit of the assay was $10^{1.5} \mathrm{TCID}_{50} / \mathrm{mL}$. Sera were analysed for serum-neutralising antibodies against CSFV using a neutralisation peroxidase-linked assay (NPLA) with SK-6 cells as described previously [34]. The CSFV neutralising antibody titres were expressed as reciprocal of the highest dilution that inhibited infection of the SK-6 cells in 50\% of four replicate cell cultures.

\subsection{Antibodies and flow cytometry}

Hybridomas for the monoclonal antibodies (mAbs) $\alpha$-CD172a /SWC3 (74-2215A), $\alpha$-CD4 (74-12-4), $\alpha$-CD8 (11/295/33), $\alpha$-CD6 (a38b2), $\alpha$-MHC class I (74-11-10), $\alpha-$ MHC class I (MSA3) and $\alpha-C D 25$ (K231.3B2) were kindly provided by Prof. Dr A. Saalmüller (Veterinary School Vienna, Austria). $\alpha$-E2 (HC/TC26) was kindly provided by Dr A.G. Bommeli (Bern, Switzerland) [14]. MAb reactions were revealed using isotype-specific phycoerythrin (PE) or biotin-conjugated anti-mouse $\operatorname{Ig}\left(\mathrm{F}\left(\mathrm{ab}^{\prime}\right) 2\right.$ fragments (Southern Biotechnology Associates, Alabama, USA) or streptavidin-Cy5 (Dako, Zug, Switzerland). Propidium iodide 
(PI; Sigma Chemicals, Buchs, Switzerland) was used at $100 \mu \mathrm{g} / \mathrm{mL}$ to identify dead cells. The cells were labelled for immunofluorescence as described previously [29], and analysed using a FACScalibur and the CellQuest Pro software (BD Biosciences, Mountain View, CA, USA).

\subsection{Isolation of $P B M C$ and generation of porcine monocyte-derived dendritic cells}

Peripheral blood mononuclear cells (PBMC) were separated using density Ficoll gradient centrifugation $(1.077 \mathrm{~g} / \mathrm{L}$; Amersham Pharmacia Biotech, AG, Dubendorf, Switzerland), as described previously [21]. Monocyte-derived dendritic cells (MoDC) were generated as described before [7]. Briefly, monocytes were enriched by magnetic cell sorting (MACS system, Miltenyi Biotec $\mathrm{GmbH}$, Bergisch Gladbach, Germany) using the anti-CD172a antibody and cultured at a concentration of $1 \times 10^{6}$ in Dulbecco modified Eagle medium (DMEM, Invitrogen, Basel, Switzerland) supplemented with $10 \%(\mathrm{v} / \mathrm{v})$ porcine serum (Sigma), $100 \mathrm{U} / \mathrm{mL}$ recombinant porcine (rp) granulocyte macrophage-colony stimulating factor (GM-CSF), kindly provided by $\mathrm{Dr}$ S. Inumaru (Institute for animal Health, Ibaraki, Japan) [16], and $100 \mathrm{U} / \mathrm{mL}$ rp IL-4, prepared in our laboratory as described previously [7]. After 3 days, the non-adherent and loosely attached cells were collected.

\subsection{Lymphoproliferation assays and antigen-presentation assays}

For the detection of CSFV-antigen-specific proliferation, PBMC $\left(2.5 \times 10^{5} /\right.$ well $)$ derived from CSFV-immune or naïve pigs were cultured in DMEM supplemented with $10 \%(\mathrm{v} / \mathrm{v})$ foetal bovine serum (FBS), $50 \mu \mathrm{M} 2$ 2-Mercapto-ethanol (2-ME) and 1\% $(\mathrm{v} / \mathrm{v})$ penicillin/streptomycin (all from Invitrogen) (referred to as complete medium) in 96-well flat-bottomed plates (Costar, Cambridge, UK) in triplicates. The cells were stimulated either with CSFV strain Eystrup (MOI 0.01 TCID $_{50} /$ cell), mock antigen derived from a lysate of uninfected SK-6 cells or with recombinant CSFV-NS3 antigen. Gp63, a Leishmania major derived protein prepared with the same expression system as NS3 was used as the negative control. Polymyxin B and lipopolysaccharide (LPS) (Escherichia coli, strain O55:B5) were purchased from Sigma. After four days of cultivation at $39{ }^{\circ} \mathrm{C}$ and $6 \% \mathrm{CO}_{2}, 1 \mu \mathrm{Ci}$ ${ }^{3} \mathrm{H}$-thymidine/well (Moravek Biochemicals Inc., Brea, CA, USA) was added for another $18 \mathrm{~h}$ to quantify the proliferative activity.

For antigen-presentation assays, MoDC of an immune pig were co-cultured with purified autologous lymphocytes $(2.5 \times$ $10^{6} / \mathrm{mL}$ ) prepared from PBMC by using immunomagnetic depletion of the CD172 $\mathrm{a}^{+}$ fraction containing monocytes and $\mathrm{DC}$ [30], or enrichment of $\mathrm{CD6}^{+} \mathrm{T}$ cells using the MACS [7]. Purity of the lymphocyte fraction was over $98 \%$. The MoDC/lymphocyte ratio was $1 / 25$. The CSFV-specific antigen NS3 was added at various concentrations to the co-cultures. Lymphoproliferation was quantified in triplicate cultures after 4 days by measuring ${ }^{3} \mathrm{H}$-thymidine uptake as described above.

The MHC restriction of the presentation of recombinant CSFV-NS3 antigen was determined using $\mathrm{mAbs}$ directed against the porcine CD4, CD8, MHC class I and MHC class II molecules. T cells were incubated with purified saturating mAbs-dilutions (hybridoma supernatants) for $1 \mathrm{~h}$ at $39^{\circ} \mathrm{C}$ before addition of the antigen and the DC.

\subsection{Interferon- $\gamma$ ELISPOT}

ELISPOT assays for the detection of IFN- $\gamma$ secreting $\mathrm{T}$ cells were performed as described elsewhere [1] with minor modifications [2]. The threshold for identification of CSFV-specific IFN- $\gamma$ spots was set at 10 spots $/ 10^{6}$ PBMC, based on tests performed with PBMC from naïve animals $(n=15)$, which were repeatedly bleeded.

\subsection{Cytotoxic $T$ cell assays}

For the stimulation of virus-specific cytotoxic $\mathrm{T}$ cells, purified lymphocytes 
from PBMC of a CSFV primed pig were prepared and co-cultured with MoDC as described above. NS3 antigen, control protein gp63, mock antigen or CSFV were added to the cultures, which were incubated for 5 days before testing for the presence of activated $\mathrm{CD} 25^{+} \mathrm{CD} 8{ }^{+} \mathrm{T}$ cells by three colour immunofluorescence flow cytometric staining [2]. The absolute number of $\mathrm{CD} 4-\mathrm{CD} 8^{\text {high }+} \mathrm{CD} 25^{\text {high }+}\left(\times 10^{6} / \mathrm{mL}\right)$ among stimulated lymphocytes was calculated as follows: absolute number of cells (calculated from the stimulated lymphocytes) multiplied with the percentage of positive cells $\left(\mathrm{CD} 4^{-} \mathrm{CD} 8^{\text {high }}+\mathrm{CD} 25^{\text {high }}\right.$ ) in mononuclear gate/100. The ratio of $\mathrm{CD}^{-}$ $\mathrm{CD} 8^{\text {high }+} \mathrm{CD} 25^{\text {high }}+$ in a total of $10^{6} \mathrm{lym}-$ phocytes was then calculated: number of CD4-CD $8^{\text {high }+} \mathrm{CD} 25^{\text {high }+} / 10^{6}$ total mononuclear harvested cells.

A flow cytometric assay for cytotoxicity was used to measure CTL responses, described previously [2]. Autologous secondary fibrocytes $(\mathrm{Fb})$ used as target cells, were stained with PKH26 according to the manufacturer's instructions (Sigma) and plated at 5000 cells/well in a 96-well flatbottomed plate. Then Fb were infected with CSFV or treated with mock antigen for $24 \mathrm{~h}$ at an MOI of 2 TCID $_{50} /$ cell. Stimulated PBMC (see above) were harvested after 5 days and added to the target cells at various effector/target ratios. After $16 \mathrm{~h}$ incubation at $39^{\circ} \mathrm{C}$, all cells were collected using trypsin-EDTA and resuspended in $150 \mu \mathrm{L}$ cell wash. Propidium iodide ( $0.1 \mu$ g, PI, Sigma) was immediately added before cytometric analysis. At least 3000 PKH26high cells were acquired for each condition and killed target cells were identified as $\mathrm{PKH} 26^{+} \mathrm{PI}^{+}$.

\section{RESULTS}

\subsection{CSFV-derived NS3 protein induces virus-specific lymphoproliferative responses}

In order to demonstrate the presence of virus-specific lymphocytes and to deter- mine the virus dose required to activate these cells, PBMC were restimulated with various doses of CSFV strain Eystrup and their proliferative response was quantified. As shown in Figure 1A a clear virus-specific stimulation without mock-induced proliferation was obtained with an m.o.i. of $0.01 \mathrm{TCID} 50 /$ cell. This virus concentration was used for further in vitro restimulation experiments described in this manuscript. The recombinant NS3 protein was tested for its capacity to induce a recall antigenspecific lymphoproliferative response. A clear response was induced in PBMC from CSFV-immune pigs, but not in cells from naïve animals (Fig. 1B). Little or no proliferative responses were noted with the Leishmania gp63 major antigen, used as the negative antigen control.

In order to exclude a role for any endotoxin present in the NS3 preparations, even though the levels were $<10 \mathrm{pg}$ endotoxin unit/ $\mu \mathrm{g}$ NS3 protein, polymyxin B was also added to the PBMC restimulating assay cultures. This did not modify the NS3-induced proliferative response (Fig. 1C). LPS was also deliberately added to the cultures, at a concentration of $10 \mathrm{pg} / \mathrm{mL}$, without an influence on the observed proliferative responses (Fig. 1C).

In addition to $\mathrm{PBMC}, \mathrm{MoDC}$ were loaded with CSFV-derived NS3 antigen (or E2) and used to stimulate isolated lymphocytes. The lymphoproliferative responses stimulated by these MoDC loaded were antigen dose-dependent, with an optimum response observed in the range of $0.5-2 \mu \mathrm{g} / \mathrm{mL}$ for the NS3 antigen (Fig. 1D).

\subsection{CSFV-derived antigens stimulate IFN- $\gamma$ secreting $T$ cells}

In order to elaborate on this in vitro response induced by the NS3 protein, the induction of IFN- $\gamma$ ELISPOT was determined using PBMC from an immune animal stimulated in vitro for $48 \mathrm{~h}$. A dosedependent induction of IFN- $\gamma$ secreting cells was noted, being at least as efficient as the virus when the higher dose was 
(A) dose-response CSFV
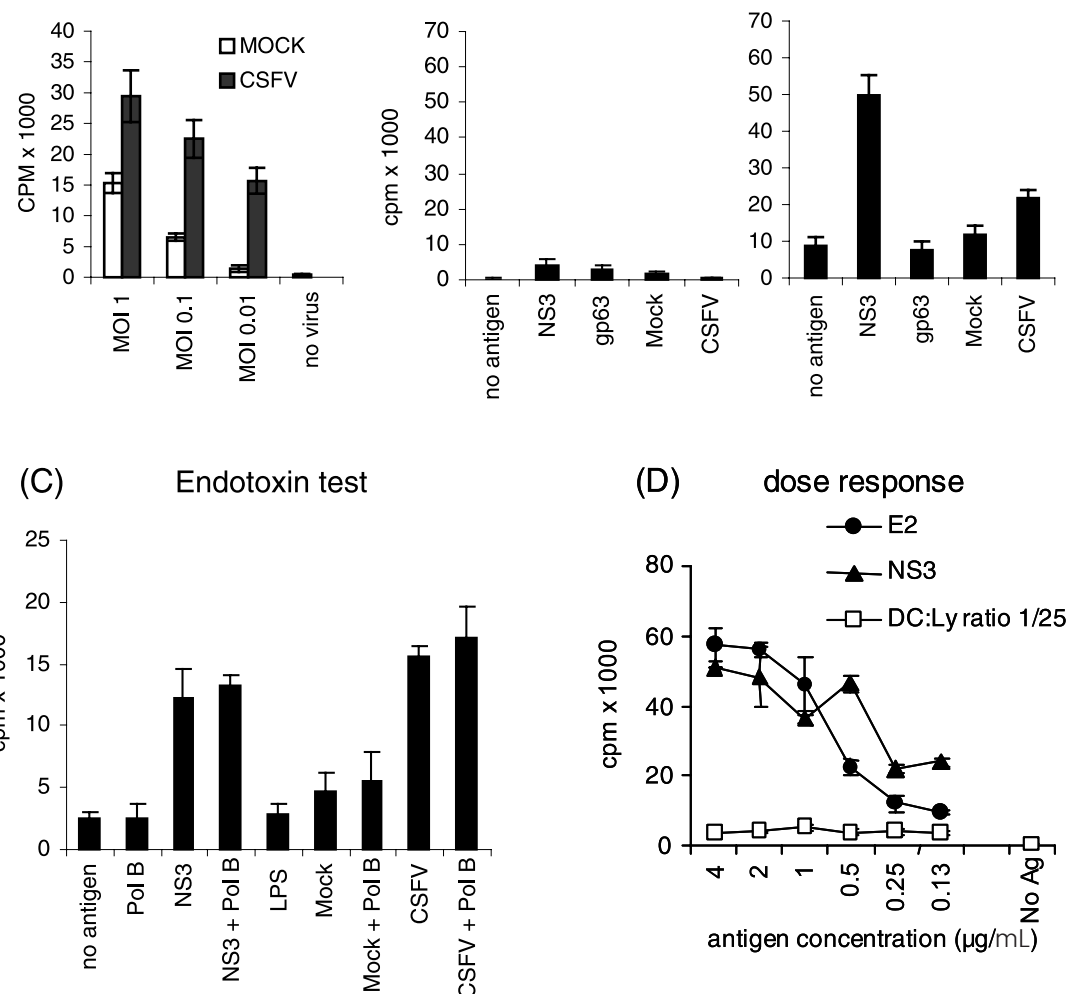

Figure 1. Lymphoproliferative responses of PBMC stimulated with CSFV and CSFV-NS3 antigen. (A) Dose-response of immune PBMC restimulated with different MOI (TCID ${ }_{50} /$ cell) of CSFV. (B) Responses of PBMC obtained from a naïve SPF pig ("primary response") and a CSFV-immune pig ("secondary response") without antigen ("no antigen"), or restimulated with NS3 $(0.5 \mu \mathrm{g} / \mathrm{mL}$ ), gp63 (0.5 $\mu \mathrm{g} / \mathrm{mL}$ ), mock-antigen or CSFV (MOI $0.01 \mathrm{TCID}_{50} /$ cell). (C) Antigen-dependent proliferation of CSFV-immune PBMC after stimulation in vitro with NS3 $(0.5 \mu \mathrm{g} / \mathrm{mL})$, mock-antigen, or CSFV (MOI $0.01 \mathrm{TCID}_{50} /$ cell), in the presence or absence of polymyxin B (Poly B; $25 \mathrm{U} / \mathrm{mL}$ ), or LPS $\left(10 \mathrm{pg} / \mathrm{mL}\right.$ ). (D) Dose response curve for E2 and NS3 antigen-specific stimulation. CD172a ${ }^{+}$ depleted lymphocytes were co-cultured with MoDC loaded with the antigens as described in Materials and Methods. The results in $\mathrm{A}$ to $\mathrm{C}$ are expressed as mean values \pm standard deviation (SD) of triplicate cultures of a representative experiment out of three.

employed (Fig. 2A). This response was only observed with PBMC isolated from a CSFV immune pig (data not shown).

The MHC restriction of this lymphoproliferative response induced by the NS3 antigen was also investigated. For this purpose, the interaction between the TCR and MHC molecules was impaired using mAbs against CD4 and CD8, molecules essential for activation of the respective $\mathrm{T}$ cell subsets. The proliferative response was clearly impaired by the anti-CD4 $\mathrm{mAb}$, whereas the anti-CD8 mAb and anti-MHC class I were less efficient. In contrast, the antiMHC class II mAb had no effect, possibly due to an insufficient concentration of the hybridoma supernatant (Fig. 2B). These results would indicate that the majority of 
(A)

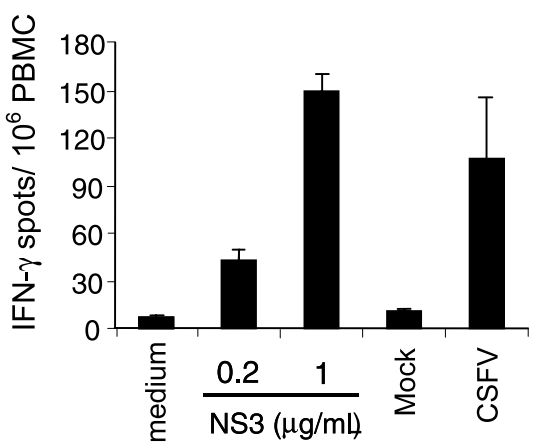

(B)

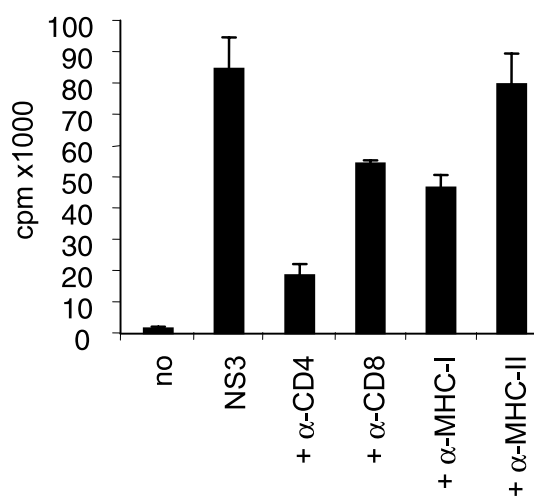

Figure 2. (A) NS3 antigen induced IFN- $\gamma$ secretion. Release of IFN- $\gamma$ from PBMC obtained from a CSFV-immune pig stimulated for $48 \mathrm{~h}$ with NS3 antigen $(0.2$ and $1 \mu \mathrm{g} / \mathrm{mL})$, mock antigen, or CSFV (MOI 0.01 TCID $_{50} /$ cell). The number of IFN- $\gamma$ spots from stimulated cultures were expressed as the mean number of spots per $10^{6}$ PBMC. (B) T-cell subset restriction of the NS3-specific T cell proliferation. MoDC/CD6 ${ }^{+}$ enriched $\mathrm{T}$ cell co-cultures obtained from a CSFV-immune pig were restimulated with NS3 antigen $(2 \mu \mathrm{g} / \mathrm{mL})$ in the presence of murine mAbs directed against CD4, CD8, MHC class I (MHC-I) and MHC class I (MHC-II). For both graphs, the means of triplicates from one representative experiment out of three \pm SD are shown.

T cells, involved in the proliferative response induced by NS3 antigen were MHC class IIrestricted $\mathrm{CD}^{+}{ }^{+}$cells, with a minor $\mathrm{MHC}$ class I-restricted CD8 ${ }^{+} \mathrm{T}$ cell component.

\subsection{NS3 induction of CSFV-specific CTL responses}

Considering the above results, the potential of the NS3 antigen to stimulate virusspecific CTLs was investigated. Activated cytotoxic T lymphocytes were identified as CD $4-C D 8^{\text {high }+}$ CD $25^{\text {hight }}$. The NS3 protein was clearly potent at activating these cells, more so than the whole virus (Fig. 3A). The analysis of the effector functions of these cells employed a flow cytometric assay for cytotoxicity, in which CSFVinfected autologous fibrocytes $(\mathrm{Fb})$ were the target cells. The cytolytic response of NS3stimulated T cells was seen to be comparable with the activity of virus-stimulated CTL effector cells (Fig. 3B). This activity was clearly higher against virus-infected targets than against mock-treated targets. There certainly was a cytolytic activity against the mock-treated targets, probably indicating NK-like activity simulated by the virus- and NS3-induced cytokines such as IFN- $\gamma$ (see Fig. 2A). Importantly, gp63 stimulated PBMC had low cytolytic activity, with no difference between infected and mock-treated targets (Fig. 3B).

\subsection{Vaccine efficacy: clinical results}

The in vitro results demonstrated that the NS3 protein has a potential as a potent antigen for CD8-restricted CTL responses. Consequently, the ability of NS3 to promote protection in vivo against CSFV was tested by performing a vaccination/challenge experiment. For this purpose, the pigs were vaccinated once with an E2 or E2/NS3 vaccine, because single shot vaccinations are sought for in efficacious emergency vaccination programmes.

Two out of four animals from the E2vaccinated group and one out of four from the E2/NS3-vaccinated animals had a transient low increase of the clinical scores (Fig. 4A). These animals showed a challenge-virus induced fever peak from 4 to 6 days post-challenge (Fig. 4B). By 7 to 8 days after challenge, all vaccinates had 


\section{(A)}
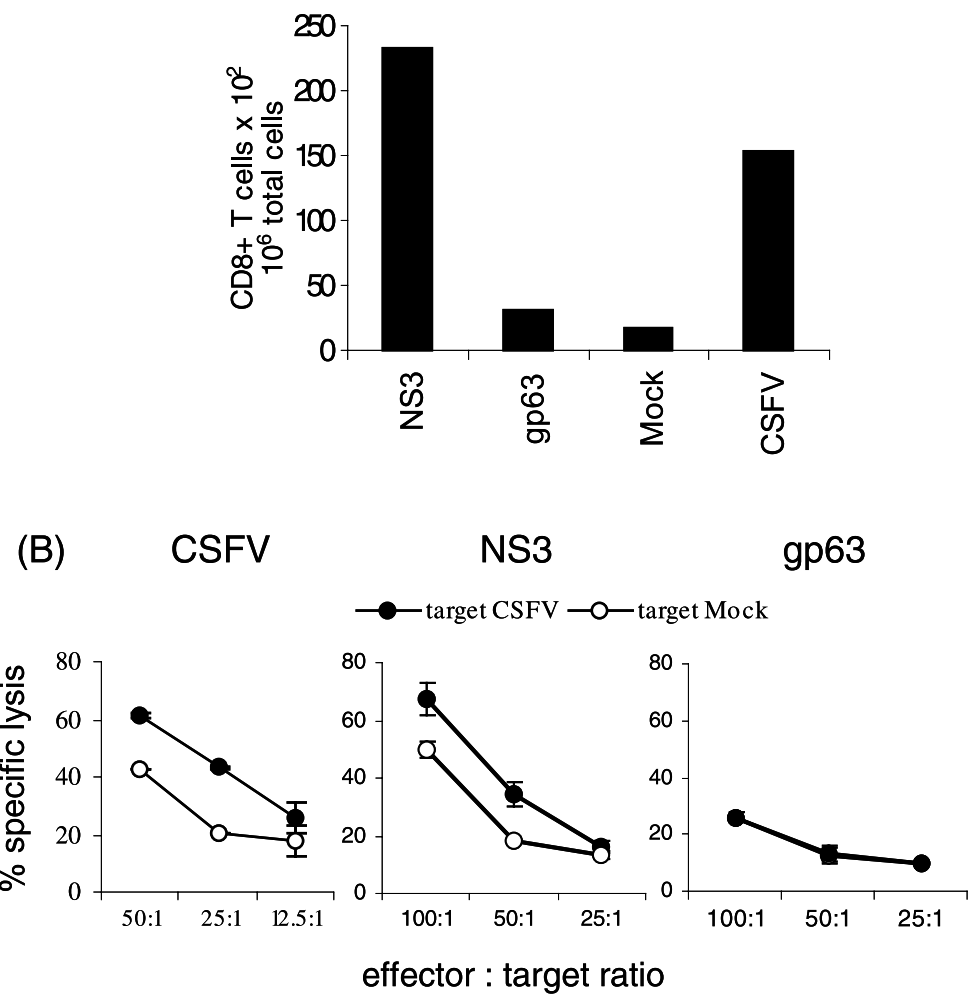

Figure 3. (A) NS3 antigen stimulation of virus-specific cytotoxic T cells. MoDC/CD172a $\mathrm{a}^{+}$depleted lymphocyte co-cultures were restimulated with NS3 antigen $(2 \mu \mathrm{g} / \mathrm{mL})$, mock-treated or infected with CSFV at a MOI of $0.01 \mathrm{TCID}_{50} /$ cell at the initiation of the co-culture. Leishmania gp63 was used as a negative control protein. After 5 days of culture, the activated CTL were identified using triple immunofluorescence analysis as $\mathrm{CD} 4{ }^{-} \mathrm{CD} 8^{\text {high }}{ }^{\mathrm{C}} \mathrm{CD} 25^{\text {hight }}$ cells. The numbers of $\mathrm{CD} 4{ }^{-}$ $\mathrm{CD} 8^{\text {high }+} \mathrm{CD} 25^{\text {high+ }}$ cells harvested from the co-cultures were expressed per $10^{6}$ total cells harvested. (B) The cytolytic activity of PBMC from a CSFV-immune pig following 5 days of in vitro restimulation with CSFV (MOI $\left.0.01 \mathrm{TCID}_{50} / \mathrm{cell}\right)$, NS3 $(2 \mu \mathrm{g} / \mathrm{mL}$ ) antigen or gp63 $(2 \mu \mathrm{g} / \mathrm{mL}$ ). This was tested using fibrocytes as target cells, which were either CSFV-infected (filled circles) or mocktreated (open circles) (MOI 2 TCID $_{50} /$ cell). The means of duplicates from one experiment out of three \pm SD are shown.

recovered clinically from CSFV clinical signs (Figs. 4A and 4B) - the one animal in the E2vaccinated group with a second fever phase at 9-11 days post-challenge probably reflected a severe inflammation of the tail following tail biting. The non-vaccinated animals developed severe symptoms of CSF, with a fever peak at 4 to 7 days post-challenge, and were euthanised when moribund at 8 days post-challenge infection.

\subsection{Vaccine efficacy: virological data}

Serum samples collected before and after the challenge infection demonstrated that after virus inoculation all control pigs developed viraemia, remaining viraemic until euthanised (Tab. I, animals \#9 and $\# 10$ ). One out of four animals vaccinated with E2 alone had a low titre of virus in the serum at 4 days post-challenge $\left(\leq 10^{2.6}\right.$ $\mathrm{TCID}_{50} / \mathrm{mL}$ serum), clearing the virus 


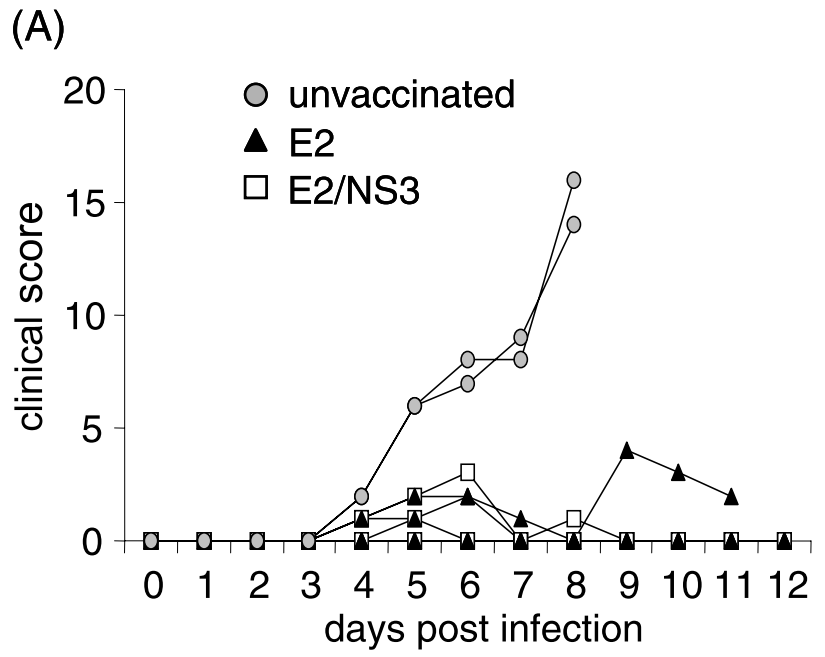

(B)

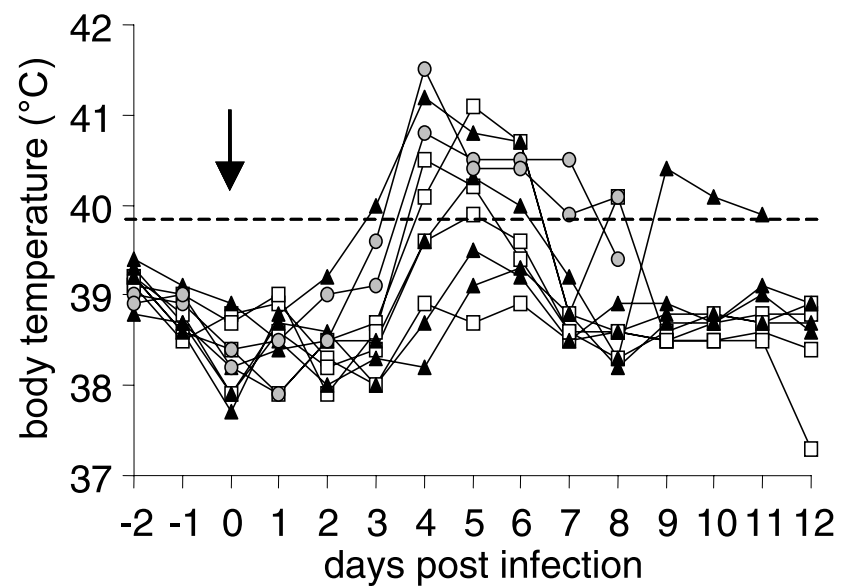

Figure 4. Clinical scores (A) and body temperatures $(\mathbf{B})$ of pigs vaccinated against CSFV with an E2-based vaccine (black filled triangles) or with an E2/NS3-based vaccine (open squares) after challenge (arrow) with virulent CSFV strain Eystrup $\left(10^{5} \mathrm{TCID}_{50} /\right.$ animal). Unvaccinated animals (grey filled circles) were used as controls.

within 7 days post-challenge (Tab. I, animal \#3). This was one of the E2-vaccinates that developed fever (see Fig. 4B). No virus was found in the serum samples of the other E2 vaccinates (Tab. I, animals \#1, \#2, \#4), nor in the sera of any E2/NS3 vaccinated animals (Tab. I, animals \#5 to \#8).

\subsection{Vaccine efficacy: immunological data}

PBMC obtained at various time-points after vaccination and challenge infection were analysed for the frequency of virusspecific IFN- $\gamma$ secreting cells by ELISPOT 
Table I. Serum virus titres ( $\mathrm{TCID}_{50} / \mathrm{mL}$ serum).

\begin{tabular}{lcccccc}
\hline \multirow{2}{*}{ Groups } & & \multicolumn{5}{c}{ Pays post challenge infection } \\
\cline { 3 - 7 } & & 4 & 7 & 11 & 14 & 18 \\
\hline E2 & $\# 1$ & n.d. $^{\mathrm{a}}$ & n.d. & n.d. & n.d. & n.d. \\
& $\# 2$ & n.d. & n.d. & n.d. & n.d. & n.d. \\
& $\# 3$ & $10^{2.6}$ & n.d. & n.d. & n.d. & n.d. \\
& $\# 4$ & n.d. & n.d. & n.d. & $\dagger^{\mathrm{b}}$ & $\dagger$ \\
E2/NS3 & $\# 5$ & n.d. & n.d. & n.d. & n.d. & n.d. \\
& $\# 6$ & n.d. & n.d. & n.d. & n.d. & n.d. \\
& $\# 7$ & n.d. & n.d. & n.d. & n.d. & n.d. \\
& $\# 8$ & n.d. & n.d. & n.d. & n.a. & n.d. \\
Unvacc. & $\# 9$ & $10^{3.3}$ & $10^{5.4}$ & $\dagger$ & $\dagger$ & $\dagger$ \\
& $\# 10$ & $10^{3.2}$ & $10^{5.8}$ & $\dagger$ & $\dagger$ & $\dagger$
\end{tabular}

a Animals euthanised for reasons of animal welfare.

${ }^{\mathrm{b}}$ Serum not available.

c Day of challenge infection.

assay. Low levels representing a virus-specific IFN- $\gamma$ response were first detected at 14 days post-vaccination in three of the four E2-vaccinates (Fig. 5). None of the E2/NS3 vaccinated animals, nor the unvaccinated controls had detectable circulating virusspecific IFN- $\gamma$ producing cells (Fig. 5). In an attempt to identify enhanced $\mathrm{T}$ helper cell responses we also checked for virusspecific $\mathrm{T}$ cells the first two weeks after challenge by the IFN- $\gamma$ ELISPOT assay. No virus-specific $\mathrm{T}$ cell responses were detectable with a reduced IFN- $\gamma$ responsiveness to the ConA mitogen control, indicating a generalised T-cell anergy.

Humoral immune responses were analysed in terms of serum virus-neutralising antibodies. Control unvaccinated animals did not develop a detectable antibody response against CSFV even after challenge infection (Tab. II, animals \#9 and \#10). Both the $\mathrm{E} 2$ and the E2/NS3 vaccines induced neutralising antibodies within 11 to 14 days post-vaccination (Tab. II, animals \#1 to \#8). At the time of challenge (14 days post-vaccination), three out of the four E2/NS3 vaccinates had titres of neutralising antibodies above 1:32 (Tab. II, animals \#5 to \#8)

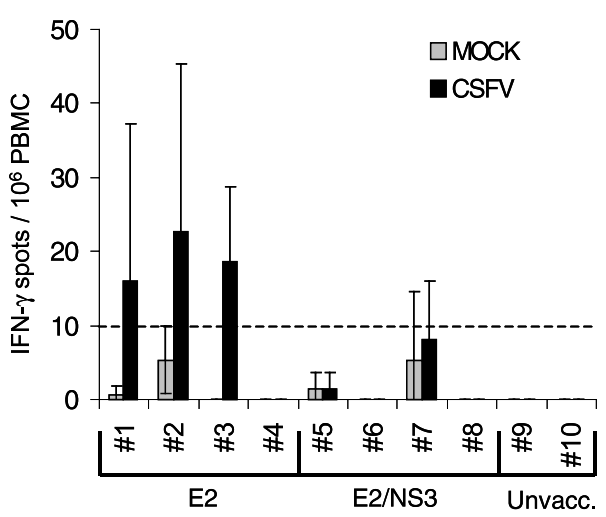

Figure 5. IFN- $\gamma$ ELISPOT of PBMC obtained from pigs 14 days post vaccination with an E2based vaccine (No. \#1 to \#4) or an E2/NS3based vaccine (No. \#5 to \#8). Unvaccinated animals (No. \#9, \#10) were used as controls. The numbers of IFN- $\gamma$ spots from CSFV stimulated cultures were expressed as the mean number of spots per $10^{6} \mathrm{PBMC}$. The dotted line represents the threshold value used for the identification of antigen-specific spots based on the values obtained before infection. The means of triplicates \pm SD are shown.

representing a critical value for protection. In contrast, only two of the E2 vaccinates (Tab. II, animals \#1 to \#4) reached this titre before challenge infection. Following challenge, all vaccinates (E2 and E2/NS3) developed a clear booster response.

Analysis of the group responses, calculated in terms of the average antibody titres of the animals in each group of vaccinates, demonstrated the efficacy of the E2/NS3 vaccine (Fig. 6). The group receiving this vaccine showed an advantage over the group of E2 vaccinates, in particular at 28 and 32 days post-vaccination (14 days postchallenge). However, it was not possible to calculate a statistical significance.

\section{DISCUSSION}

Prevention and control of outbreaks caused by the highly contagious CSFV are implemented by stamping out-methods, vaccination, or a combination of the two. The 
Table II. Titres of serum-neutralising antibodies after vaccination and challenge infection.

\begin{tabular}{|c|c|c|c|c|c|c|c|c|c|c|}
\hline \multirow{2}{*}{ Groups } & \multirow{2}{*}{ Pigs } & \multicolumn{9}{|c|}{ Days post vaccination } \\
\hline & & 0 & 7 & 11 & $14^{\mathrm{c}}$ & 18 & 21 & 25 & 28 & 32 \\
\hline \multirow[t]{5}{*}{ E2 } & $\# 1$ & $\leq 10$ & $\leq 10$ & 56 & 80 & 134 & 451 & 12162 & 8590 & 14454 \\
\hline & \#2 & $\leq 10$ & $\leq 10$ & 112 & 268.5 & 640 & 640 & 7228 & 7228 & 7228 \\
\hline & $\# 3$ & $\leq 10$ & $\leq 10$ & $\leq 10$ & 10 & 56 & 640 & 17179 & 14454 & 24322 \\
\hline & $\# 4$ & $\leq 10$ & $\leq 10$ & $\leq 10$ & 19.9 & 67 & 451 & 10240 & $\dagger^{\mathrm{a}}$ & $\dagger$ \\
\hline & $\# 5$ & $\leq 10$ & $\leq 10$ & 11.9 & 33.6 & 750 & 758.5 & 7228 & 758.5 & 20480 \\
\hline $\mathrm{E} 2 /$ & $\# 6$ & $\leq 10$ & $\leq 10$ & 28 & 223.8 & 1496 & 7228 & 17179 & 28840 & 34356 \\
\hline \multirow[t]{2}{*}{ NS3 } & $\# 7$ & $\leq 10$ & $\leq 10$ & 8.4 & 67 & 457 & 4217 & 12162 & 20480 & 17179 \\
\hline & $\# 8$ & $\leq 10$ & $\leq 10$ & 11.9 & 28 & 158 & 451 & 7228 & n.a. ${ }^{b}$ & 20480 \\
\hline \multirow[t]{2}{*}{ Unvacc. } & \#9 & $\leq 10$ & $\leq 10$ & $\leq 10$ & $\leq 10$ & $\leq 10$ & $\leq 10$ & $\dagger$ & $\dagger$ & $\dagger$ \\
\hline & $\# 10$ & $\leq 10$ & $\leq 10$ & $\leq 10$ & $\leq 10$ & $\leq 10$ & $\leq 10$ & $\dagger$ & $\dagger$ & $\dagger$ \\
\hline
\end{tabular}

a Animals euthanised for reasons of animal welfare.

b Serum not available.

${ }^{c}$ Day of challenge infection.

design of new efficacious vaccines against CSFV requires knowledge concerning the host's immune response towards the respective pathogen. This is particularly pertinent if emergency vaccination is to be an adjunct to stamping-out in the face of an outbreak.

One critical step in the development of virus vaccines is the identification of antigenic subunits stimulating the necessary arms of immune defences to result in the protection of the host against infection. Most studies have concentrated on the humoral immune response of CSFV-infected animals, and a protective value for the appearance of neutralising antibodies with a titre of at least 1:32 has been observed [33]. Nevertheless, with viruses such as CSFV which produce a non-cytopathic infection in cells, and can thus persist in the host, one must consider both cytotoxic (CTL) and humoral (B lymphocyte) responses in the induction of protective immunity. T cell epitopes relating to the induction of virusspecific cytotoxic $\mathrm{T}$ lymphocytes have been identified on non-structural proteins of CSFV $[1,25]$. Consequently, the present work analysed for the first time porcine in vitro and in vivo immune responses against the recombinant non-structural NS3 protein of CSFV. This was pursued in the light of the

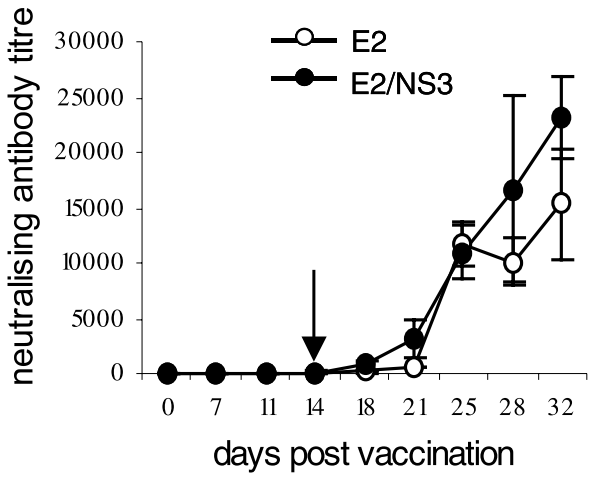

Figure 6. Group average for the titres of the neutralising antibodies in the serum of pigs immunised with an E2-based vaccine (open circles) or an E2/NS3-based vaccine (filled circles) after vaccination (day 0 ) and challenge (arrow, day 14). The results are expressed as the mean of four animals per group \pm standard error $(\mathrm{SE})$.

NS3 protein being a candidate antigen containing CTL epitopes for an improved protein-based CSFV subunit vaccine.

The recombinant NS3 protein was seen to be a potent $\mathrm{T}$ cell antigen, in terms of inducing lymphoproliferation, IFN- $\gamma$ production and effector CTL responses. In addition to the latter observation demonstrating the induction of $\mathrm{CD}^{+} \mathrm{T}$ cells, the 
NS3 protein activated T helper cells, witnessed by the sensitivity of the induced lymphoproliferation to anti-CD4 Ab blocking. Overall, induction of the $T$ cell responses by NS3, especially the stimulated effector CTL, was comparable to the whole virus, indicating that NS3 contains immunodominant CTL epitope(s). This demonstrates that viral NS3 contains CTL epitopes in addition to the NS2 [1] and NS4 proteins [25].

Due to these promising in vitro results, the efficacy and protective capacity of the recombinant NS3 protein when combined with E2 were tested. It is important to include the E2, due to the observations that neutralising antibodies are essential for protective immune responses - these antibodies are directed against the viral E2 protein $[4,24,33]$. In the present study, the results obtained on protection of pigs immunised with the E2-based vaccine is consistent with previous results [4, 24]. When compared with protection mediated by the E2/ NS3-based vaccine, only slight differences were noted. While two of the E2 vaccinates showed a transient augmentation of clinical scores after the challenge infection, only one of the E2/NS3 vaccinates was in this situation. A low titre viraemia was detected in one of the E2 vaccinates, but only at a single time-point, whereas none of the E2/NS3 vaccinates had viraemia. The E2/NS3 vaccinates showed a slight advantage in terms of neutralising antibody titres, but the difference from the E2 vaccinates was not statistically significant. A possible explanation for this trend towards an increased antibody response in pigs immunised with the E2/NS3-based vaccine would be the additional stimulation of NS3-specific $\mathrm{CD}^{+}$ $\mathrm{T}$ cells, which could contribute in the activation of E2-specific B cells. Interestingly, certain vaccinates showed neutralising antibody titres below the desired threshold of $1: 32$ at the time of challenge infection, yet were still protected. Similar results were observed using live C-strain vaccines [8, $35]$. All vaccinates showed a clear booster antibody response after the challenge infection, consistent with the findings of others [4].

In conclusion, recombinant NS3 protein has clear in vitro antigenic potential, stimulating $\mathrm{T}$ helper cell activity and in particular promoting cytotoxic $\mathrm{T}$ cell responses. Translation of this in vivo was not so straightforward. Addition of NS3 to an E2 vaccine did not apparently modify detectable cellular or humoral immunity. This may have reflected an insensitivity for detecting the in vivo responses, because the in vitro results demonstrated NS3 induction of virus-specific IFN- $\gamma$ secreting cells which were not identifiable in vivo. The low frequency of virus-specific IFN- $\gamma$ producing cells following $\mathrm{E} 2$ vaccination demonstrates the difficulty of detecting $\mathrm{T}$-cell responses in the peripheral blood following protein vaccination. In this situation the lack of response in the E2/NS3 vaccinates does not necessarily reflect an absence of T-cell responses but could result from a difference in the kinetics of effector cell presence in blood circulation. Nevertheless, it can be concluded that a likely scenario is that translation of the in vitro antigenic potential of NS3 to the in vivo situation requires an appropriate delivery of the NS3 to antigen presenting cells (APC) enabling cross-presentation to $\mathrm{CD}^{+} \mathrm{T}$ cells. One potential alternative formulation concept which should mediate cross-presentation is the use of delivery vehicles such as virus-like particles (VLP) [3], immune complexes [26], ISCOMS [19, 32] or bacterial toxin-delivery into the APC cytoplasm $[6,9,18]$. Alternatively, DNA vaccination approaches could possibly be improved by addition of the NS3 gene. Certain of these delivery systems are currently under study with other virus/antigen systems, and may well prove potentially applicable to numerous virus vaccines including CSFV vaccines.

Another field requiring additional investigations is the improvement of the current DIVA tests. Although, the detection of antibodies against $E^{\text {rns }}$ indicate an infection, the sensitivity of these tests are not as high as 
those detecting E2, reflecting that E2 represents a major antigenic protein for the induction of neutralising antibodies.

\section{ACKNOWLEDGEMENTS}

We thank V. Tache and B. Hermann for excellent technical assistance, $\mathrm{H}$. Gerber for $\mathrm{mAb}$ preparations, $\mathrm{V}$. Neuhaus for preparing of recombinant cytokines and Dr N. Ruggli for helpful discussions. For animal care and regular bleeding we are grateful to P. Zulliger, A. Michel, D. Brechbühl and H.-P. Lüthi. This work was supported by the Swiss Federal Office for Education and Science (Project BBW-No. 00.0635 linked to EU project QLK2-CT-200101374 and Project BBW-No. 00.0636 linked to EU project QLK2-CT-2001-01346).

\section{REFERENCES}

[1] Armengol E., Wiesmuller K.H., Wienhold D., Buttner M., Pfaff E., Jung G., Saalmuller A., Identification of T-cell epitopes in the structural and non-structural proteins of classical swine fever virus, J. Gen. Virol. 83 (2002) 551-560.

[2] Balmelli C., Ruggli N., McCullough K., Summerfield A., Fibrocytes are potent stimulators of anti-virus cytotoxic T cells, J. Leukoc. Biol. (2005) 923-933.

[3] Boisgerault F., Moron G., Leclerc C., Viruslike particles: a new family of delivery systems, Expert Rev. Vaccines 1 (2002) 101109.

[4] Bouma A., de Smit A.J., de Kluijver E.P., Terpstra C., Moormann R.J., Efficacy and stability of a subunit vaccine based on glycoprotein E2 of classical swine fever virus, Vet. Microbiol. 66 (1999) 101-114.

[5] Bouma A., de Smit A.J., De Jong M.C., de Kluijver E.P., Moormann R.J., Determination of the onset of the herd-immunity induced by the E2 sub-unit vaccine against classical swine fever virus, Vaccine 18 (2000) 13741381

[6] Carbonetti N.H., Irish T.J., Chen C.H., O’Connell C.B., Hadley G.A., McNamara U., Tuskan R.G., Lewis G.K., Intracellular delivery of a cytolytic T-lymphocyte epitope peptide by pertussis toxin to major histocompatibility complex class I without involvement of the cytosolic class I antigen processing pathway, Infect. Immun. 67 (1999) 602-607.
[7] Carrasco C.P., Rigden R.C., Schaffner R., Gerber H., Neuhaus V., Inumaru S., Takamatsu H., Bertoni G., McCullough K.C., Summerfield A., Porcine dendritic cells generated in vitro: morphological, phenotypic and functional properties, Immunology 104 (2001) 175-184.

[8] Dahle J., Liess B., Assessment of safety and protective value of a cell culture modified strain "C" vaccine of hog cholera/classical swine fever virus, Berl. Munch. Tierarztl. Wochenschr. 108 (1995) 20-25.

[9] De Haan L., Hearn A.R., Rivett A.J., Hirst T.R., Enhanced delivery of exogenous peptides into the class I antigen processing and presentation pathway, Infect. Immun. 70 (2002) 3249-3258.

[10] de Smit A.J., Laboratory diagnosis, epizootiology, and efficacy of marker vaccines in classical swine fever: a review, Vet. Q. 22 (2000) 182-188.

[11] Dewulf J., Laevens H., Koenen F., Mintiens K., de Kruif A., An E2 sub-unit marker vaccine does not prevent horizontal or vertical transmission of classical swine fever virus, Vaccine 20 (2001) 86-91.

[12] Edwards S., Fukusho A., Lefevre P.C., Lipowski A., Pejsak Z., Roehe P., Westergaard J., Classical swine fever: the global situation, Vet. Microbiol. 73 (2000) 103-119.

[13] Floegel-Niesmann G., Classical swine fever (CSF) marker vaccine. Trial III. Evaluation of discriminatory ELISAs, Vet. Microbiol. 83 (2001) 121-136.

[14] Greiser-Wilke I., Moennig V., Coulibaly C.O., Dahle J., Leder L., Liess B., Identification of conserved epitopes on a hog cholera virus protein, Arch. Virol. 111 (1990) 213225.

[15] Hulst M.M., Westra D.F., Wensvoort G., Moormann R.J., Glycoprotein E1 of hog cholera virus expressed in insect cells protects swine from hog cholera, J. Virol. 67 (1993) 5435-5442.

[16] Inumaru S., Kokuho T., Denham S., Denyer M.S., Momotani E., Kitamura S., Corteyn A., Brookes S., Parkhouse R.M., Takamatsu H., Expression of biologically active recombinant porcine GM-CSF by baculovirus gene expression system, Immunol. Cell Biol. 76 (1998) 195-201.

[17] Knoetig S.M., Summerfield A., SpagnuoloWeaver M., McCullough K.C., Immunopathogenesis of classical swine fever: role of monocytic cells, Immunology 97 (1999) 359366.

[18] Lippolis J.D., Denis-Mize K.S., Brinckerhoff L.H., Slingluff C.L. Jr., Galloway D.R., 
Engelhard V.H., Pseudomonas exotoxinmediated delivery of exogenous antigens to MHC class I and class II processing pathways, Cell. Immunol. 203 (2000) 75-83.

[19] Maloy K.J., Donachie A.M., Mowat A.M., Induction of $\mathrm{Th} 1$ and $\mathrm{Th} 2 \mathrm{CD}^{+} \mathrm{T}$ cell responses by oral or parenteral immunization with ISCOMS, Eur. J. Immunol. 25 (1995) 2835-2841.

[20] Mayer D., Thayer T.M., Hofmann M.A., Tratschin J.D., Establishment and characterisation of two cDNA-derived strains of classical swine fever virus, one highly virulent and one avirulent, Virus Res. 98 (2003) 105-116.

[21] McCullough K.C., Schaffner R., Fraefel W., Kihm U., The relative density of CD44-positive porcine monocytic cell populations varies between isolations and upon culture and influences susceptibility to infection by African swine fever virus, Immunol. Lett. 37 (1993) 83-90.

[22] Mittelholzer C., Moser C., Tratschin J.D., Hofmann M.A., Analysis of classical swine fever virus replication kinetics allows differentiation of highly virulent from avirulent strains, Vet. Microbiol. 74 (2000) 293-308.

[23] Moennig V., Introduction to classical swine fever: virus, disease and control policy, Vet. Microbiol. 73 (2000) 93-102.

[24] Moormann R.J., Bouma A., Kramps J.A., Terpstra C., De Smit H.J., Development of a classical swine fever subunit marker vaccine and companion diagnostic test, Vet. Microbiol. 73 (2000) 209-219.

[25] Pauly T., Elbers K., Konig M., Lengsfeld T., Saalmuller A., Thiel H.J., Classical swine fever virus-specific cytotoxic $\mathrm{T}$ lymphocytes and identification of a T cell epitope, J. Gen. Virol. 76 (1995) 3039-3049.

[26] Regnault A., Lankar D., Lacabanne V., Rodriguez A., Thery C., Rescigno M., Saito T., Verbeek S., Bonnerot C., Ricciardi-Castagnoli P., Amigorena S., Fcgamma receptor-mediated induction of dendritic cell maturation and major histocompatibility complex class Irestricted antigen presentation after immune complex internalization, J. Exp. Med. 189 (1999) 371-380.

[27] Ruggli N., Tratschin J.D., Mittelholzer C., Hofmann M.A., Nucleotide sequence of classical swine fever virus strain Alfort/187 and transcription of infectious RNA from stably cloned full-length cDNA, J. Virol. 70 (1996) 3478-3487.

[28] Saatkamp H.W., Berentsen P.B., Horst H.S., Economic aspects of the control of classical swine fever outbreaks in the European Union, Vet. Microbiol. 73 (2000) 221-237.

[29] Summerfield A., McCullough K.C., Porcine bone marrow myeloid cells: phenotype and adhesion molecule expression, J. Leukoc. Biol. 62 (1997) 176-185.

[30] Summerfield A., Guzylack-Piriou L., Schaub A., Carrasco C.P., Tache V., Charley B. McCullough K.C., Porcine peripheral blood dendritic cells and natural interferon-producing cells, Immunology 110 (2003) 440-449.

[31] Suradhat S., Intrakamhaeng M., Damrongwatanapokin S., The correlation of virus-specific interferon-gamma production and protection against classical swine fever virus infection, Vet. Immunol. Immunopathol. 83 (2001) 177-189.

[32] Takahashi H., Takeshita T., Morein B., Putney S., Germain R.N., Berzofsky J.A., Induction of $\mathrm{CD}^{+}$cytotoxic $\mathrm{T}$ cells by immunization with purified HIV-1 envelope protein in ISCOMs, Nature 344 (1990) 873-875.

[33] Terpstra C., Wensvoort G., The protective value of vaccine-induced neutralising antibody titres in swine fever, Vet. Microbiol. 16 (1988) 123-128.

[34] Terpstra C., Bloemraad M., Gielkens A.L., The neutralizing peroxidase-linked assay for detection of antibody against swine fever virus, Vet. Microbiol. 9 (1984) 113-120.

[35] Terpstra C., Woortmeyer R., Barteling S.J., Development and properties of a cell culture produced vaccine for hog cholera based on the Chinese strain, Dtsch. Tierarztl. Wochenschr. 97 (1990) 77-79.

[36] Van Oirschot J.T., Vaccinology of classical swine fever: from lab to field, Vet. Microbiol. 96 (2003) 367-384.

[37] Van Rijn P.A., Bossers A., Wensvoort G., Moormann R.J., Classical swine fever virus (CSFV) envelope glycoprotein E2 containing one structural antigenic unit protects pigs from lethal CSFV challenge, J. Gen. Virol. 77 (1996) 2737-2745

[38] Van Zijl M., Wensvoort G., de Kluyver E., Hulst M., van der Gulden H., Gielkens A., Berns A., Moormann R., Live attenuated pseudorabies virus expressing envelope glycoprotein E1 of hog cholera virus protects swine against both pseudorabies and hog cholera, J. Virol. 65 (1991) 2761-2765.

[39] Zinkernagel R.M., Hengartner H., On immunity against infections and vaccines: credo 2004, Scand. J. Immunol. 60 (2004) 9-13. 